\title{
Synthesis, characterization and cytotoxic activity of 5- aminotetrazole Schiff bases
}

\author{
Ukpe AJIMA $^{1 *}$, Johnson Ogoda ONAH ${ }^{1}$, Mary Tuga KUJE ${ }^{1}$, David Mohammed UMAR $^{2}$, \\ Vuyisa MZOZOYANA ${ }^{3}$ and Stephen Olalekan OJERINDE ${ }^{1}$ \\ ${ }^{1}$ Department of Pharmaceutical \& Medicinal Chemistry; ${ }^{2}$ Department of Clinical Pharmacy \& Pharmacy \\ Practice; Faculty of Pharmaceutical Sciences, University of Jos, PMB 2084, Jos. Nigeria. \\ ${ }^{3}$ School of Chemistry and Physics, University of KwaZulu-Natal, Westville, Durban. South Africa.
}

Received 21 ${ }^{\text {st }}$ August 2020; Accepted $11^{\text {th }}$ October 2020

\begin{abstract}
The incidence and prevalence of cancer has been on the rise in recent years and this has been linked to environmental factors, adoption of westernized lifestyle and aging populations. This situation is further complicated by the inadequacies of currently used anticancer agents such as toxicity and resistance which has prompted the search for new and more effective drugs. In this study, Schiff bases of 5-aminotetrazole were prepared by condensing 5aminotetrazole with various aromatic aldehydes. Preliminary confirmation of compound formation was done using thin layer chromatography while FT-IR, UV-Visible, proton and carbon-13 NMR spectroscopy were used for structural characterization of the compounds. The cytotoxicity of the compounds was evaluated using the brine shrimp lethality assay. The compounds were synthesized in good yield ranging from 80 to $88 \%$ and found to be soluble in polar solvents. Results of the spectroscopic analyses were indicative of the formation of the new compounds. The 5aminotetrazole Schiff bases were found to demonstrate considerable cytotoxicity compared to the standard drug used, with the $o$-vanillin Schiff base (OVASB) showing the highest cytotoxicity $\left(\mathrm{LC}_{50} 0.23 \mu \mathrm{g} / \mathrm{mL}\right.$ ). The results indicate that the compounds have potential for further development in the search for safe and potent anticancer agents.
\end{abstract}

Keywords: Cancer; Schiff base; 5-Aminotetrazole; Aromatic aldehydes; Brine shrimp assay

\section{INTRODUCTION}

Cancer or malignant neoplasm is a group of diseases in which a group of cells display uncontrolled growth, invade adjacent cells and can even metastasize to distant sites [1]. It is a serious public health problem throughout the world and is the second leading cause of human death globally after cardiovascular diseases [2]. In the year 2018, cancer was reported to be responsible for about 9.6 million deaths, with approximately $70 \%$ of deaths due to the disease occurring in low- and middle-income countries [3]. In Nigeria in the same year, available statistics show that there were about 115,950 new cases of cancer with 70,327 deaths [4]. Currently, the main treatment options for cancer include radiotherapy, surgery, immunotherapy and chemotherapy [5]. Some of the classes of chemotherapeutic agents that are used in

*Correspondence. E-mail: descar84@yahoo.com Tel: +234-7031284923.

ISSN 0189-8442

$\S$ Author's name corrected from previous version in which the name was wrongly arranged/spelt

(cc) BY-Ne 2021. Published by Faculty of Pharmaceutical Sciences, University of Jos, Nigeria. Under Creative Commons Attribution-Non-Commercial 4.0 International License. https://creativecommons.org/licenses/by-nc/4.0/ 
anticancer therapy include: alkylating agents (e.g. cyclophosphamide), antimetabolites (e.g. methotrexate), natural products (e.g. vincristine), hormonal agents (e.g. diethylstilbestrol), signal transduction inhibitors (e.g. lapatinib), anti-angiogenesis agents (e.g. sorafenib) and enzymes like Lasparaginase [6]. However, existing chemotherapeutic agents are limited by a number of factors such as severe and debilitating side effects and the development of resistance, usually after repeated use [7]. It is therefore important to develop new, safe and more effective drugs for treating cancer. Schiff bases are aldehyde or ketone derivatives in which the carbonyl group is replaced by an imine or azomethine group [8]. They are widely used in industry and have also been found to exhibit a broad range of biological activities such as antifungal [9], antiinflammatory [10], Antileishmanial [11], antimicrobial [12-14], anti- cancer [15-17]. The tetrazole nucleus is well recognized in medicinal chemistry as a privileged scaffold due to its unique structural features and electronic properties [18]. As a result, this nucleus can be found in a large number of approved and marketed drugs such as antiviral, anti-inflammatory and anticonvulsants [19]. This nucleus has also been found to have anticancer activity [20,21]. Furthermore, it has been shown that derivatization of certain molecules via Schiff base formation has the potential to boost their anticancer activity [22, 23] and it was therefore hypothesized that synthesis of Schiff bases of the tetrazole pharmacophore may produce a new class of molecules with enhanced cytotoxic activity and this formed the basis for this study. The present study is therefore aimed at synthesizing a number of 5-amino tetrazole Schiff bases and carrying out preliminary evaluation of their anticancer potential using the Brine shrimp lethality assay.

\section{EXPERIMENTAL METHODS}

Instruments. Melting points $\left({ }^{\circ} \mathrm{C}\right)$ were recorded on Gallenkamp melting point apparatus and are uncorrected. Ultraviolet (UV) Spectra were recorded on Jenway 7315 Spectrometer, Fourier Transform Infra-Red (FTIR) Spectra were recorded on a Bruker Invenio-R spectrometer, Nuclear Magnetic Resonance (NMR) spectra were recorded on a Bruker Avance 400 spectrometer at frequencies of $400 \mathrm{MHz}$ and $100 \mathrm{MHz}$ for ${ }^{1} \mathrm{H}$, ${ }^{13} \mathrm{C}$ respectively.

Chemicals/ reagents. The reagents: 5aminotetrazole, 3-hydroxybenzaldehyde, $o$ vanillin and benzaldehyde were obtained from Sigma Aldrich, Germany. The solvents (methanol, ethyl acetate, hexane, dichloromethane, absolute ethanol, glacial acetic acid, dimethyl sulfoxide) were all analytical grade, obtained from the same source and used without further purification. Thin layer chromatography (TLC) was done using aluminum backed, Silica gel 60A F $\mathrm{F}_{254}$ TLC plates, Fluorochem, United Kingdom.

\section{Synthesis of the Schiff bases}

Synthesis of 5-Aminotetrazole/o-vanillin Schiff Base. A 0.56-gram portion of 5aminotetrazole was weighed and dissolved in $60 \mathrm{~mL}$ of absolute ethanol in a refluxing flask. Then 1 gram of $o$-vanillin was dissolved in 40 $\mathrm{mL}$ of absolute ethanol and slowly added to the 5 -aminotetrazole solution with continuous stirring. Glacial acetic acid (4 mL) was added to the resultant mixture and refluxed for 8 hours. Thereafter, the reaction mixture was cooled to room temperature, filtered, the precipitate dried and recrystallized from ethanol.

Synthesis of 5-aminotetrazole/3-hydroxy benzaldehyde Schiff base. A 0.697-gram sample of 5-aminotetrazole was weighed and dissolved in $60 \mathrm{~mL}$ of absolute ethanol in a refluxing flask. Then 1 gram of 3hydroxybenzaldehyde was dissolved in $40 \mathrm{~mL}$ of absolute ethanol and slowly added to the 5- 
aminotetrazole solution with continuous stirring. Glacial acetic acid $(4 \mathrm{~mL})$ was added to the resultant mixture and refluxed for 8 hours. Thereafter, the reaction mixture was cooled to room temperature, filtered, the precipitate dried and recrystallized from ethanol.

\section{Synthesis of 5-aminotetrazole/benzaldehyde} Schiff base. A 0.697-gram sample of 5aminotetrazole was weighed and dissolved in $60 \mathrm{~mL}$ of absolute ethanol in a refluxing flask. Then $1 \mathrm{~mL}$ of benzaldehyde was dissolved in $40 \mathrm{~mL}$ of absolute ethanol and slowly added to the 5-aminotetrazole solution with continuous stirring. Glacial acetic acid (4 mL) was added to the resultant mixture and refluxed for 8 hours. Thereafter, the reaction mixture was cooled to room temperature, filtered, the precipitate dried and recrystallized from ethanol.

Solubility test. Qualitative solubility tests were carried out on the synthesized Schiff bases in a range of solvents with different polarities such as hexane, dichloromethane, ethyl acetate and methanol.

Spectroscopic characterization. The compounds were characterized using Ultraviolet (UV), Fourier transform infra-red (FTIR), Proton and Carbon-13 NMR spectroscopy.

Brine shrimp lethality assay. Brine shrimp cytotoxicity assay is widely used in the bioassay for the bioactive compounds. The assay was carried out according to the principle and protocol previously described [24]. The cytotoxicity screening of the extract was carried against a simple zoological organism, brine shrimp nauplii. Artemia salina Leach (brine shrimp) eggs were placed in a small tank containing $3.8 \%$ non-iodized $\mathrm{NaCl}$ solution (sea water) for two days to hatch the shrimp eggs and to be matured as nauplii. The compound $(4.0 \mathrm{mg}$ ) was dissolved in DMSO (dimethyl sulfoxide). Then $100 \mu \mathrm{L}$ of solution was taken into a test tube containing $5 \mathrm{~mL}$ of sea water and 10 shrimp nauplii. Thus, final concentration of the first test tube solution was $400 \mu \mathrm{g} / \mathrm{mL}$. Then a series of solutions of varying concentrations was prepared from the stock solution by serial dilution. Thus, the concentrations of the obtained solution in each test tube were 400, 200, 100, 50, 25, 12.5, 6.25, 3.12 and $1.56 \mu \mathrm{g} / \mathrm{mL}$ for 9 dilutions. $1.0 \mathrm{mg}$ of cyclophosphamide (served as the positive control) was dissolved in distilled water to get an initial concentration of $100 \mu \mathrm{g} / \mathrm{mL}$ from which serial dilutions was made using sea water prepared to get $100,50,25,12.5,6.25$, $3.12,1.56,0.781$ and $0.391 \mu \mathrm{g} / \mathrm{mL}$. The positive control solutions contained 10 living brine shrimp nauplii in $5 \mathrm{ml}$ sea water. For negative control, $100 \mu 1$ of DMSO was added to each of the pre-marked test tubes containing $5 \mathrm{ml}$ of sea water and 10 shrimp nauplii. The vials were maintained under illumination. Survivors were counted after 24 hours and the percentage mortality at each vial and control was determined using the equation: \% mortality $=$ (no. of dead nauplii/ initial no. of live nauplii) $x$ 100. The concentrationmortality data was analyzed statistically by using probit analysis for the determination of $\mathrm{LC}_{50}$ values and linear regression for the fractions and $\mathrm{LC}_{50}$ values less than $100 \mathrm{ppm}$ (or $100 \mu \mathrm{g} / \mathrm{mL}$ ) was considered significant and toxic.

\section{RESULTS}

Some physico-chemical properties of the Schiff bases including their melting points, rf values and yield obtained after synthesis and purification are displayed in Table 1 while Table 2 shows the result of the solubility assessment of the compounds in various solvents. Table 3 shows the results of the brine shrimp lethality assay displayed as median lethal concentration $\left(\mathrm{LC}_{50}\right)$ of the compounds. The spectroscopic data for the compounds are also displayed below. 
U. Ajima et al. / J. Pharmacy \& Bioresources 18(1), 32-39(2021)

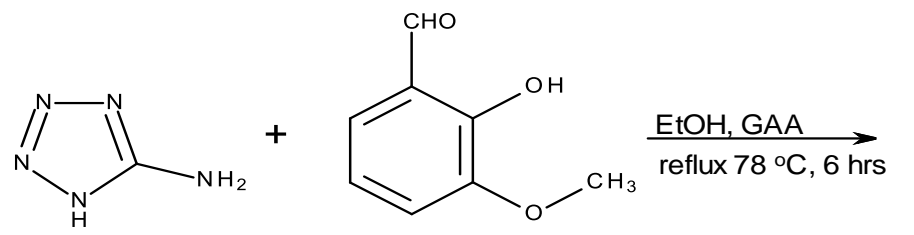

o-vanillin<smiles>COc1cccc(/C=N/c2nnn[nH]2)c1O</smiles>

OVASB

Scheme 1: Synthesis of 5-Aminotetrazole/o-Vanillin Schiff Base<smiles>Nc1nnn[nH]1</smiles>

5-aminotetrazole<smiles>O=Cc1cccc(O)c1</smiles>

3-hydroxybenzaldehyde
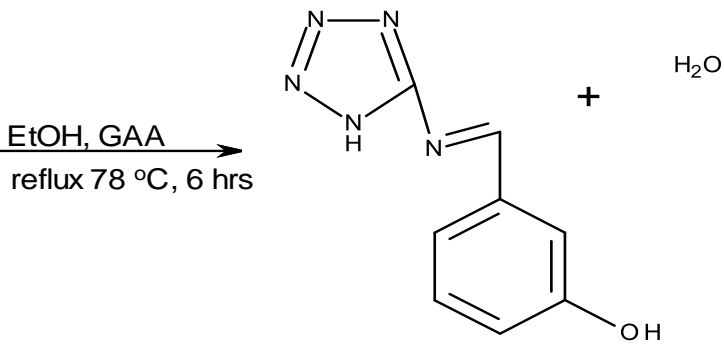

HBSB

Scheme 2: Synthesis of 5-Aminotetrazole//3-hydroxybenzaldehyde Schiff base<smiles>Nc1nnn[nH]1</smiles>

5 -aminotetrazole<smiles>O=Cc1ccccc1</smiles>

3-hydroxybenzaldehyde

\section{$\mathrm{EtOH}, \mathrm{GAA}$ \\ reflux $78^{\circ} \mathrm{C}, 6 \mathrm{hrs}$}

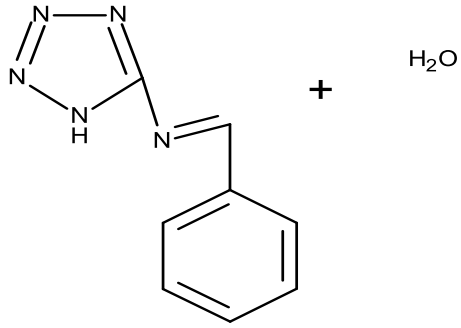

BZSB

Scheme 3: Synthesis of 5-Aminotetrazole//benzaldehyde Schiff base

Table 1: Physico-chemical properties of the Schiff bases

\begin{tabular}{lllll}
\hline Compound Code & Molecular Formula & Melting Point $\left({ }^{\circ} \mathrm{C}\right)$ & $\%$ Yield & Rf value \\
\hline OVASB & $\mathrm{C}_{9} \mathrm{H}_{9} \mathrm{~N}_{5} \mathrm{O}_{2}$ & $180-182$ & $88 \%$ & 0.76 \\
HBSB & $\mathrm{C}_{8} \mathrm{H}_{7} \mathrm{~N}_{5} \mathrm{O}$ & $171-173$ & $80 \%$ & 0.74 \\
BZSB & $\mathrm{C}_{8} \mathrm{H}_{7} \mathrm{~N}_{5}$ & $202-203$ & $82 \%$ & 0.75 \\
\hline
\end{tabular}

OVASB $=5$-aminotetrazole $/ o$-vanillin Schiff Base, HBSB $=5$-aminotetrazole / 3-hydroxybenzaldehyde Schiff

Base, BZSB = 5-aminotetrazole / benzaldehyde Schiff Base. TLC Solvent system: Petroleum Ether: Ethanol (1:1).

Table 2: Result of solubility tests on the Schiff bases

\begin{tabular}{lccc}
\hline Solvent & OVASB & HBSB & BZSB \\
\hline Methanol & Soluble & Soluble & Soluble \\
Dichloromethane & Insoluble & Insoluble & Insoluble \\
Ethyl acetate & Insoluble & Insoluble & Insoluble \\
Hexane & Insoluble & Insoluble & Insoluble \\
\hline
\end{tabular}

Spectroscopic data for the Schiff bases 
2-methoxy-6-\{[(1H-tetrazol-5-yl)imino]methyl $\}$ phenol (OVASB)

UV-Vis $(\mathrm{MeOH}) \lambda_{\max }: 245 \mathrm{~nm}$.

FTIR (neat) $v\left(\mathrm{~cm}^{-1}\right)$ : 3384 (O-H str.), 3190 (N-H str.), 2937 (C-H str.-saturated), 1666 (C=N str.), 1587 (C=C str.), 1375 (N=N str.), 1263 (C-N str.).

${ }^{1} \mathrm{H}$ NMR $(400 \mathrm{MHz}, \mathrm{MeOD}): \delta(\mathrm{ppm}) 9.78(1 \mathrm{H}, \mathrm{d}), 7.46(1 \mathrm{H}, \mathrm{t}), 6.97(1 \mathrm{H}, \mathrm{d}), 3.95(3 \mathrm{H}, \mathrm{s})$.

${ }^{13} \mathrm{C}$ NMR (100 MHz, MeOD): $\delta$ (ppm) 193.04, 192.99, 154.73, 149.73, 130.73, 127.94, 116.37, 111.45, 56.48.

3-\{[(1H-tetrazol-5-yl)imino]methyl $\}$ phenol (HBSB)

UV-Vis $(\mathrm{MeOH}) \lambda_{\max }: 245 \mathrm{~nm}$.

FTIR (neat) $v\left(\mathrm{~cm}^{-1}\right)$ : 3339 (O-H str.), 3190 (N-H str.), 2959 (C-H str.-saturated.), 1666 (C=N str.), 1580 (C=C str.), 1356 ( $\mathrm{N}=\mathrm{N}$ str.), 1282 (C-N str.).

${ }^{1} \mathrm{H}$ NMR $(400 \mathrm{MHz}, \mathrm{MeOD}): \delta(\mathrm{ppm}) 9.91(1 \mathrm{H}, \mathrm{s}), 7.40(1 \mathrm{H}, \mathrm{m}), 7.31(1 \mathrm{H}, \mathrm{d}), 7.11(1 \mathrm{H}, \mathrm{d})$.

${ }^{13} \mathrm{C}$ NMR (100 MHz, MeOD): $\delta$ (ppm) 194.41, 194.35, 159.45, 139.47, 131.30, 123.03, 122.84, 115.86.

1-phenyl-N-(1H-tetrazol-5-yl)methanimine (BZSB)

UV-Vis $(\mathrm{MeOH}) \lambda_{\max }: 240 \mathrm{~nm}$.

FTIR (neat) $v\left(\mathrm{~cm}^{-1}\right)$ : 3190 (N-H str.), 3071 (C-H str.-unsaturated), 2929 (C-H str.-saturated.), 1640 (C=N str.), 1602 $(\mathrm{C}=\mathrm{C}$ str.), 1319 (N=N str.), 1203 (C-N str.).

${ }^{1} \mathrm{H}$ NMR (400 MHz, MeOD) : $\delta(\mathrm{ppm}) 8.04(1 \mathrm{H}, \mathrm{d}), 7.61(2 \mathrm{H}, \mathrm{t}), 7.48(2 \mathrm{H}, \mathrm{t}), 6.33(1 \mathrm{H}, \mathrm{s})$.

${ }^{13} \mathrm{C}$ NMR (100 MHz, MeOD): $\delta$ (ppm) 170.11, 158.24, 134.09, 131.96, 130.73, 130.22, 129.49, 129.17.

Table 3: Results of brine shrimp lethality assay

\begin{tabular}{ll}
\hline Compound & $\mathrm{LC}_{50}(\mu \mathrm{g} / \mathrm{mL})$ \\
\hline OVASB & $0.23 \pm 0.15$ \\
HBSB & $0.59 \pm 0.16$ \\
BZSB & $0.33 \pm 0.21$ \\
Cyclophosphamide (Standard) & $0.09 \pm 0.02$ \\
\hline
\end{tabular}

The $\mathrm{LC}_{50}$ values are expressed as mean $\pm \mathrm{SEM}, \mathrm{n}=10$ in each group and were determined using Finney Probit analysis via SPSS 17.0 software.

\section{DISCUSSION}

The Schiff bases were obtained in good yield ranging from 80 to $88 \%$ (Table 1) and this yield is higher than that obtained in a previous study $(17-87 \%)$ where antimicrobial Schiff bases of 5-amino tetrazole were prepared [14]. The Schiff bases were found to be poorly soluble in non-polar solvents but soluble in polar solvents such as methanol (Table 2) and this is a useful property with respect to their distribution in vivo since the physiological milieu is mostly made up of water. However, for a compound to have good bioavailability, it must possess reasonable balance between hydrophilicity and lipophilicity and this may imply that the compounds may need to be further optimized to improve their lipohilicity.

The spectroscopic data prove that the compounds were successfully synthesized and the results are in agreement with published data for the component molecules [25,26]. Also, occurrence of the key transformation which involved reaction between the aldehyde and amine functional groups to form the imine was backed up by the spectroscopic data. For instance, the $o$-vanillin Schiff base of 5aminotetrazole (OVASB) showed maximum UV absorption at a wavelength of $245 \mathrm{~nm}$. Ordinarily, the electronic spectrum of unsubstituted tetrazole is characterized by an absorption band with a maximum in the vacuum UV region ( $\lambda_{\max }$ below $200 \mathrm{~nm}$ ). However, conjugation of the tetrazole nucleus with the benzene ring of $o$-vanillin led to a considerable red shift of the maximum into the normal UV range. In the FTIR spectrum of the compound, the Carbon-Nitrogen stretching band of the newly formed imine bond can be seen at $1666 \mathrm{~cm}^{-1}$. It was also observed that the strong carbonyl stretching band of the aldehyde usually seen around $1700 \mathrm{~cm}^{-1}$ 
together with the two signals around 2700 and $2800 \mathrm{~cm}^{-1}$ of the aldehydic $\mathrm{C}-\mathrm{H}$ and the two sharp spikes of the primary amine signal at about $3300 \mathrm{~cm}^{-1}$ had all disappeared and these observations are indicative of the formation of the new Schiff base. Some other bands for the compound that can be seen in the IR spectrum include the broad $\mathrm{O}-\mathrm{H}$ stretch band at $3384 \mathrm{~cm}^{-}$ ${ }^{1}$ and the $\mathrm{C}=\mathrm{C}$ stretch at $1587 \mathrm{~cm}^{-1}$ and the $\mathrm{C}$ $\mathrm{H}$ stretch aliphatic at $2937 \mathrm{~cm}^{-1}$. In the ${ }^{1} \mathrm{H}$ NMR, a signal at $9.78 \mathrm{ppm}$ as a doublet belongs to the aromatic proton at position 4 of the aromatic ring and it has experienced a strong downfield shift from the usual values due to the deshielding effect arising from its close proximity to the strongly electronegative oxygen atom of the methyl ether substituent at position 3 of the aromatic ring while the triplet at $7.46 \mathrm{ppm}$ can be attributed to the aromatic proton at position 5 of the aromatic ring. The doublet at 6.97 is attributable to the aromatic proton at position 6 while the singlet at 3.95 is attributable to the three protons of the methyl ether substituent at position 3 of the aromatic ring. The imine and phenolic protons of the compound are exchangeable and since the compounds were characterized using a protic deuterated solvent $\left(\mathrm{CD}_{3} \mathrm{OD}\right)$, the $\mathrm{NH}$ and $\mathrm{OH}$ protons were exchanged with deuterium and the peaks disappeared completely and were not seen on the spectrum. In the ${ }^{13} \mathrm{C}-\mathrm{NMR}$, the signal at $193.04 \mathrm{ppm}$ belongs to the imine carbon $(\mathrm{C}=\mathrm{N})$ while the signal at 192.99 is due to the single Carbon atom of the tetrazole ring. The signals at 154.72 and 149.73 are due to the oxygen bearing Carbon atoms of the aromatic rings i.e. Carbon 2 and 3 respectively. The resonances for the other unsubstituted aromatic carbon atoms can be seen at 130.73, 127.94, 116.37 and $111.45 \mathrm{ppm}$ while the methyl carbon atom of the methyl ether substituent at position 3 of the aromatic ring gave a signal at the most upfield position of $56.48 \mathrm{ppm}$. Similar assignments were done for the other compounds (HBSB and BZSB) which are structurally similar to OVASB with slight differences in substitution around the aromatic ring.

The results of the Brine shrimp lethality assay shown in table 3 indicate that all the compounds possess cytotoxic activity with $\mathrm{LC}_{50}$ values in the range $0.23-0.59 \mu \mathrm{g} / \mathrm{mL}$. Of all the compounds, the $o$-vanillin Schiff base (OVASB) was found to be the most active having the lowest $\mathrm{LC}_{50}$ value of $0.23 \mu \mathrm{g} / \mathrm{mL}$. In exploring the structure-activity relationships among this group of Schiff bases, it was observed that the o-vanillin Schiff base which possessed multiple substitutions on the benzene ring was the most active. It possesses a hydroxyl group at the ortho position and a methoxy group at the meta position. It is believed that the methoxy group at the meta position exerts an electron withdrawing effect thereby reducing the electron density in the aromatic system which may be beneficial for cytotoxic activity. The hydroxyl group at the ortho position is electron donating but its effect may be moderated by steric effects due to its closeness to the imine substitution on the Benzene ring. The trend mentioned above is further supported by the observation that removal of the methoxy group and moving the hydroxyl group to the meta position which enhances the electron density in the Benzene ring is not beneficial and results in a decline in cytotoxic activity as seen by the higher $\mathrm{LC}_{50}$ of the HBSB Schiff base. When the Benzene ring is unsubstituted as seen in BZSB, the cytotoxicity is intermediate and the conclusion that can be reached from the above substitution is that for this class of Schiff bases, introduction of electron withdrawing substituents on the aromatic ring will lead to enhanced cytotoxic activity. It was further observed that all the compounds were less cytotoxic when compared to the standard anticancer agent cyclophosphamide and this implies that there is still room for further structural modification to improve their potency and activity. 
Conclusion. The synthesis and cytotoxicity evaluation of several 5-aminotetrazole Schiff bases has been reported. The compounds showed moderate cytotoxic activity with the $o$ vanillin Schiff base having the highest activity. The structure-activity relationships (SAR) within the class of compounds were also examined in order to provide a guide for the systematic design of more active candidates.

\section{REFERENCES}

1. Sarkar S, Horn G, Moulton K, Oza A, Byler S, Kokolus S, et al. Cancer development, progression, and therapy: an epigenetic overview. Int J Mol Sci. 2013 Oct $21 ; 14(10): 21087-113$.

2. Chalbatani GM, Dana H, Memari F, Gharagozlou E, Ashjaei S, Kheirandish P, et al. Biological function and molecular mechanism of piRNA in cancer. Pract Lab Med. 2019;13:e00113.

3. World Health Organization. Global health estimates 2016: deaths by cause, age, sex, by country and by region, 2000-2016. [Internet]. World Health Organization, Geneva, Switzerland. 2018 [cited 2019 Apr 9]. Available from: https://www.who.int/healthinfo/global_burden_disea se/en/

4. IACR. Nigeria - Cancer Country Profile 2020 [Internet]. World Health Organization, Geneva, Switzerland. 2020 [cited 2020 Mar 7]. p. 1-2. Available from: https://www.who.int/cancer/countryprofiles/NGA_2020.pdf?ua=1

5. Baxi SM, Beall R, Yang J, Mackey TK. A multidisciplinary review of the policy, intellectual property rights, and international trade environment for access and affordability to essential cancer medications. Global Health. 2019;15(1):57.

6. Finch GL, Burns-Naas LA. Cancer Chemotherapeutic Agents. In: Wexler PBT, editor. Encyclopedia of Toxicology. 3rd Edition. Oxford: Academic Press; 2014. p. 630-41.

7. Szakács G, Paterson JK, Ludwig JA, BoothGenthe C, Gottesman MM. Targeting multidrug resistance in cancer. Nat Rev Drug Discov. 2006;5(3):219-34.

8. Ganguly A, Chakraborty P, Banerjee K, Choudhuri SK. The role of a Schiff base scaffold, N(2-hydroxy acetophenone) glycinate-in overcoming multidrug resistance in cancer. Eur J Pharm Sci. 2014;51:96-109.
9. Isloor AM, Kalluraya B, Shetty P. Regioselective reaction: Synthesis, characterization and pharmacological studies of some new Mannich bases derived from 1,2,4-triazoles. Eur J Med Chem. 2009;44(9):3784-7.

10. Rakesh KP, Manukumar HM, Gowda DC. Schiff's bases of quinazolinone derivatives: Synthesis and SAR studies of a novel series of potential antiinflammatory and antioxidants. Bioorg Med Chem Lett. 2015;25(5):1072-7.

11. Rando DG, Avery MA, Tekwani BL, Khan SI, Ferreira EI. Antileishmanial activity screening of 5nitro-2-heterocyclic benzylidene hydrazides. Bioorg Med Chem. 2008;16(14):6724-31.

12. Makawana JA, Sun J, Zhu H-L. Schiff's base derivatives bearing nitroimidazole moiety: New class of antibacterial, anticancer agents and potential EGFR tyrosine kinase inhibitors. Bioorg Med Chem Lett. 2013;23(23):6264-8.

13. Raparti V, Chitre T, Bothara K, Kumar V, Dangre S, Khachane C, et al. Novel 4-(morpholin-4yl)-N'-(arylidene)benzohydrazides: Synthesis, antimycobacterial activity and QSAR investigations. Eur J Med Chem. 2009;44(10):3954-60.

14. Afolabi E, Galaya S. Comparison of antimicrobial activity of six 5-amino tetrazole Schiff bases with their corresponding oxazepine derivatives. J Pharm Bioresour. 2013;10(2):52-5.

15. Demirci S, Doğan A, Başak N, Telci D, Dede B, Orhan C, et al. A Schiff base derivative for effective treatment of diethylnitrosamine-induced liver cancer in vivo. Anticancer Drugs. 2015 Jun;26(5):555-64.

16. Ameri A, Khodarahmi G, Forootanfar H, Hassanzadeh F, Hakimelahi G-H. Hybrid Pharmacophore Design, Molecular Docking, Synthesis, and Biological Evaluation of Novel Aldimine-Type Schiff Base Derivatives as Tubulin Polymerization Inhibitor. Chem Biodivers. 2018 Mar 1;15(3):e1700518.

17. Tahlan S, Narasimhan B, Lim SM, Ramasamy K, Mani V, Shah SAA. 2-Mercaptobenzimidazole Schiff Bases: Design, Synthesis, Antimicrobial Studies and Anticancer Activity on HCT-116 Cell Line. Mini Rev Med Chem. 2019;19(13):1080-92.

18. Butler RN. 4.17 - Tetrazoles. In: Katritzky AR, Rees CW, Scriven EF, editors. Comprehensive Heterocyclic Chemistry II. Oxford: Pergamon; 1996. p. 621-78.

19. Mahmood A, Khan IU, Longo RL, Irfan A, Shahzad SA. Synthesis and structure of 1-benzyl-5- 
amino-1H-tetrazole in the solid state and in solution: Combining X-ray diffraction, 1H NMR, FT-IR, and UV-Vis spectra and DFT calculations. Comptes Rendus Chim. 2015;18(4):422-9.

20. Hładoń B, Laskowska H, Sloderbach A, Melzer E. In vitro cytostatic activity of 1,2,4-triazoloand 1,2,3,4-tetrazolo pyridazines. Pol J Pharmacol. 1997;49(6):471-7.

21. Bavetsias V, Marriott JH, Melin C, Kimbell R, Matusiak ZS, Boyle FT, et al. Design and Synthesis of Cyclopenta[g]quinazoline-Based Antifolates as Inhibitors of Thymidylate Synthase and Potential Antitumor Agents,. J Med Chem. 2000 May 1;43(10):1910-26.

22. Shinohara Y, Endo Y, Abe C, Shiba I, Ishizuka M, Tanaka T, et al. Development of a novel Schiff base derivative for enhancing the anticancer potential of 5-aminolevulinic acid-based photodynamic therapy. Photodiagnosis Photodyn Ther. 2017 Dec;20:182-8.
23. Zhang L, Chen Q, Hou G, Zhao W, Hou Y. Hydroxyl-substituted double Schiff-base condensed 4-piperidone/cyclohexanones as potential anticancer agents with biological evaluation. J Enzyme Inhib Med Chem. 2019 Dec;34(1):264-71.

24. Meyer BN, Ferrigni NR, Putnam JE, Jacobsen LB, Nichols DE, McLaughlin JL. Brine Shrimp: A Convenient General Bioassay for Active Plant Constituents. Planta Med. 1982;45(05):31-4.

25. Ostrovskii VA, Koldobskii GI, Trifonov RE. 6.07 - Tetrazoles. In: Katritzky AR, Ramsden CA, Scriven EF V, Taylor RJ, editors. Comprehensive Heterocyclic Chemistry I I I. Oxford: Elsevier; 2008. p. 257-423.

26. Shneshil MK, Ibraheem TK, Jamal MY. Synthesis and Antioxidant Activity of Some Schiff's Bases Fused With Tetrazole Ring. J Appl Chem. 2014;3(5):1945-50. 